\title{
En route to a dianilinyl-substituted carbo-cyclohexadiene with promising electrical properties
}

Oleg Lozynskyi ${ }^{\mathrm{a}}$, Cécile Barthes ${ }^{\mathrm{b}}$, Arnaud Rives $^{\mathrm{b}}$, Valérie Maraval $^{\mathrm{b} *}$, Zoia V. Voitenko ${ }^{\mathrm{a}}$, Remi Chauvin $^{\mathrm{b} *}$

${ }^{a}$ Department of Chemistry, Taras Shevchenko National University of Kyiv, Volodymyrska Street, 64/13, Kyiv 01601, Ukraine

${ }^{\mathrm{b}}$ CNRS, LCC (Laboratoire de Chimie de Coordination), 205 route de Narbonne, BP 44099, F31077 Toulouse Cedex 4, France

Université de Toulouse, UPS, ICT-FR 2599, 31062 Toulouse Cedex 9, France. valerie.maraval@lcc-toulouse.fr, chauvin@lcc-toulouse.fr

Keywords: Butatrienes, carbo-cyclohexadiene, carbo-mers, macrocyclization, single molecule conductance.

The macro-aromatic carbo-benzene core para-disubstituted by 4-anilinyl groups is known to be an efficient single-molecule conductor, exhibiting a conductance of $106 \mathrm{nS}$ measured by the scanning tunneling microscopy-break junction technique. The linear carbo-butadiene analogue bearing the same anilinyl substituents was found to be less efficient, with a conductance of $2.7 \mathrm{nS}$. The reason of this difference could be elucidated through the study of the charge transport properties of a cyclically locked carbo-butadiene core in a carbo-cyclohexadiene derivative. In this paper, advances in the synthesis of this challenging dianilinyl-substituted carbo-cyclohexadiene are presented.

\section{Introduction}

After the first example of carbo-cyclohexadiene 1 [1,2], a substituted 1,3-cyclohexadiene isolated as a side product of the incomplete reductive aromatization of the hexaoxy[6]pericyclyne 2 [3] to the paradianisyl-carbo-benzene 3 [1,4], a series of 1,10diversely substituted carbo-cyclohexadienes $\mathbf{1 F}$ was very recently accessed through a specific design [5]. This strategy is based on the introduction of trifluoromethyl substituents at two adjacent vertices of [6]pericyclynic precursors $\mathbf{2 F}$, thus preventing the formation of one of the three butatriene moieties in the corresponding carbo-benzenes during reductive treatment with $\mathrm{SnCl}_{2} / \mathrm{HCl}$ (Scheme 1).

Recent studies by the scanning tunneling microscopy-break junction (STM-BJ) technique [6] evidenced the remarkable single-molecule conductance (SMC) of anilinyl-substituted carbo-mers and in particular of carbo-benzene 4 exhibiting a SMC value of $106 \mathrm{nS}$ over $2 \mathrm{~nm}$ 
[7]. For comparison, this value is $c a$ ten times the conductance of a shorter hexabenzocoronene analogue [8], and $c a 40$ times that of the acyclic dianilinyl-carbo-butadiene analogue 5 of similar length $(\approx 1.9 \mathrm{~nm})[4 \mathrm{~g}, 9]$ (Figure 1). This large difference in conductance between $\mathbf{4}$ and $\mathbf{5}$ can be proposed to be due to topological and/or geometrical features, ie to the participation of a single conduction pathway in $\mathbf{5} v s$ two in $\mathbf{4}$, and/or to the flexibility-allowed non planarity of the DBA core. To bring light on this point, efforts have been devoted to the synthesis of the dianilinyl-carbo-cyclohexadiene $\mathbf{6}$ having a unique conduction pathway, as $\mathbf{5}$, but locked in a rigid macrocycle as in $\mathbf{4}$ (Figure 1).

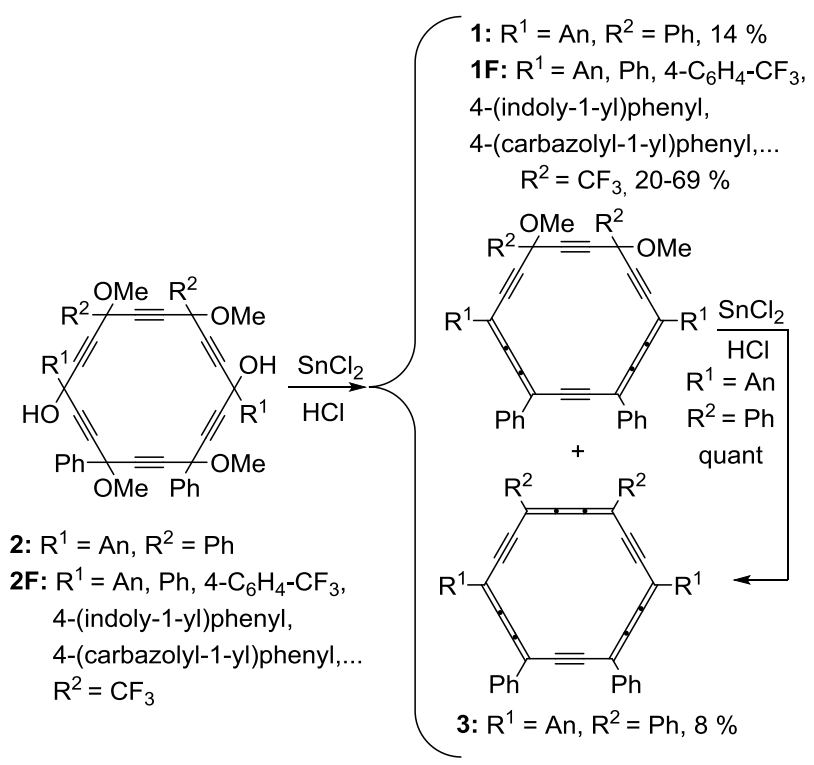

Scheme 1. Synthesis of carbo-cyclohexadienes $\mathbf{1}$ and $\mathbf{1 F}$ from [6]pericyclynic precursors $\mathbf{2}$ and $\mathbf{2 F}$ respectively $[1,5] . \mathrm{An}=4-\mathrm{C}_{6} \mathrm{H}_{4}-\mathrm{OMe}$

The synthetic strategies previously developed for the preparation of related bistrifluoromethylated carbo-cyclohexadienes $[1,5]$ proved however not applicable to the preparation of $\mathbf{6}$. Recent progress calling for alternative strategies towards this challenging target are reported hereafter.

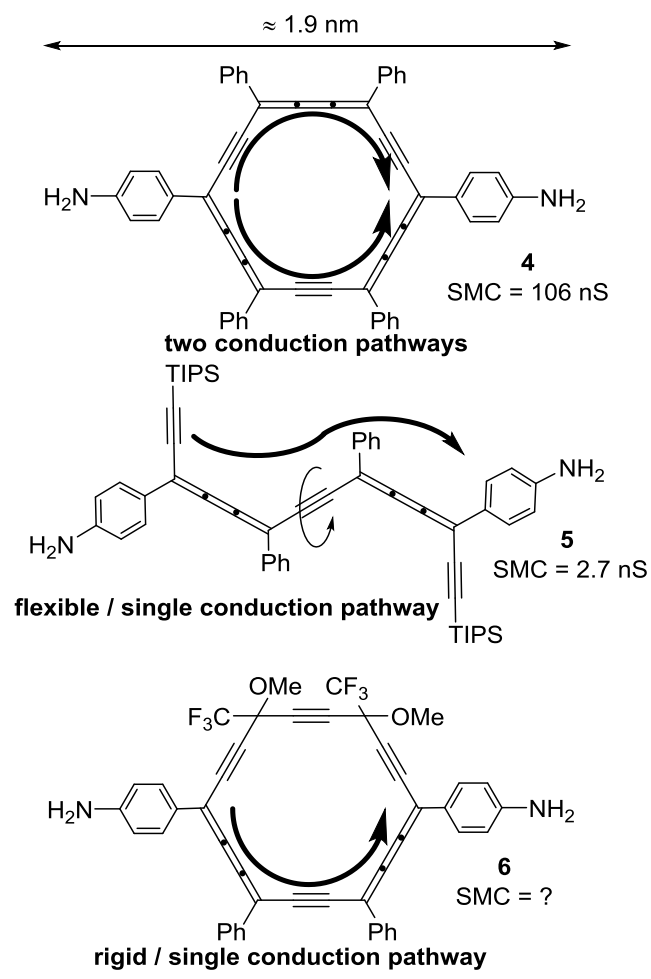

Figure 1. Dianilinyl-substituted DBA derivatives for SMC.

\section{Results and discussion}

In a previous report on the preparation of the dianilinyl-carbo-benzene $\mathbf{4}$ and carbobutadiene $\mathbf{5}$, it has been evidenced that the aminophenyl substituents have to be anchored to the DBA core in a late stage because of the poor stability of the intermediates bearing anilinyl functions, even protected with trimethylsilyl groups $[4 \mathrm{~g}]$. Therefore, the [6]pericyclynedione precursor 7 should be reacted with the protected anilinyl substituents at the last step, just before the final reduction to the carbo-cyclohexadiene 6. First attempts at 
preparing the diketone 7 through the use of either a $[8 \mathrm{~F}+10]$ or a $[8+10 \mathrm{~F}]$ macrocyclization procedure from a $\mathrm{C}_{8}$ triyne and a $\mathrm{C}_{10}$ dialdehyde however failed to produce the targeted bissecondary [6]pericyclynediol precursor 8 [5] (Scheme 2). Since the same approach had proved to be efficient for the preparation of the perphenylated analog of $\mathbf{7}$, the failure of this method in the bis-trifluoromethylated series can be imputed to the effect of the $\mathrm{CF}_{3}$ groups on the reactivity of the $\mathrm{C}_{8}$ and $\mathrm{C}_{10}$ reactants.

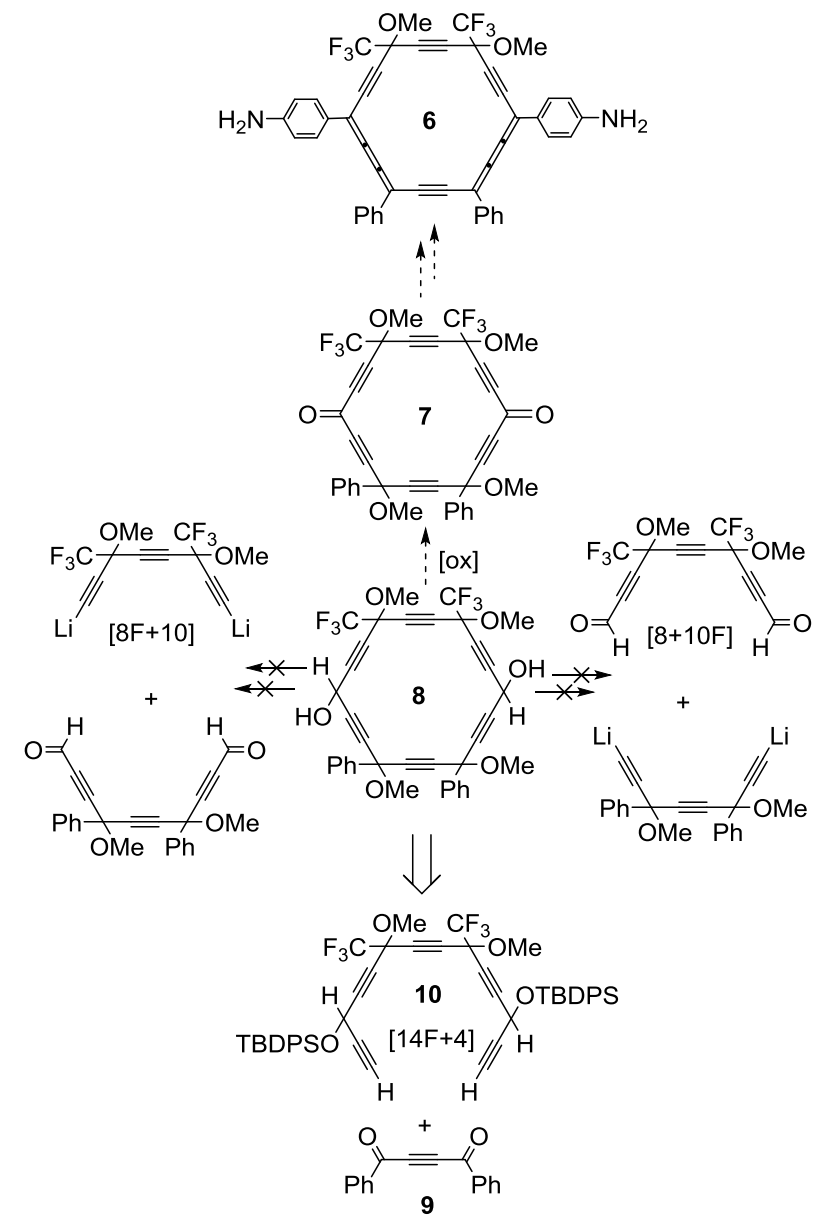

Scheme 2. Envisaged synthetic approaches to the [6]pericyclynedione 7, precursor of the bistrirfluoromethylated carbo-cyclohexadiene 6.

An alternative $[14 \mathrm{~F}+4]$ macrocyclization strategy was thus envisaged from the $\mathrm{C}_{4}$ dibenzoylacetylene $9[10]$ and the $\mathrm{C}_{14}$ bistrifluoromethylated pentayne 10. The synthesis of the latter was first attempted from the known triyne 11 [5] (Scheme 3). The first step consisted in the addition of the dilithium salt of 11 to two equivalents of trimethylsilylpropynal, itself prepared by a known procedure from lithium trimethylsilylacetylide and DMF [4f, 11]. In spite of a moderate stability, the bissecondary diol product $\mathbf{1 2}$ was isolated in $47 \%$ yield. Protection of the two $\mathrm{OH}$ groups with silyl substituents was then achieved by treatment of 12 with TBDPSCl and DMAP, giving 13 in $38 \%$ yield. Attempt at selective desilylation of the two alkyne termini of $\mathbf{1 3}$, using either $\mathrm{K}_{2} \mathrm{CO}_{3}$ in methanol, or $\mathrm{AgNO}_{3} /$ lutidine afforded undetermined polymeric materials only, instead of $\mathbf{1 0 .}$

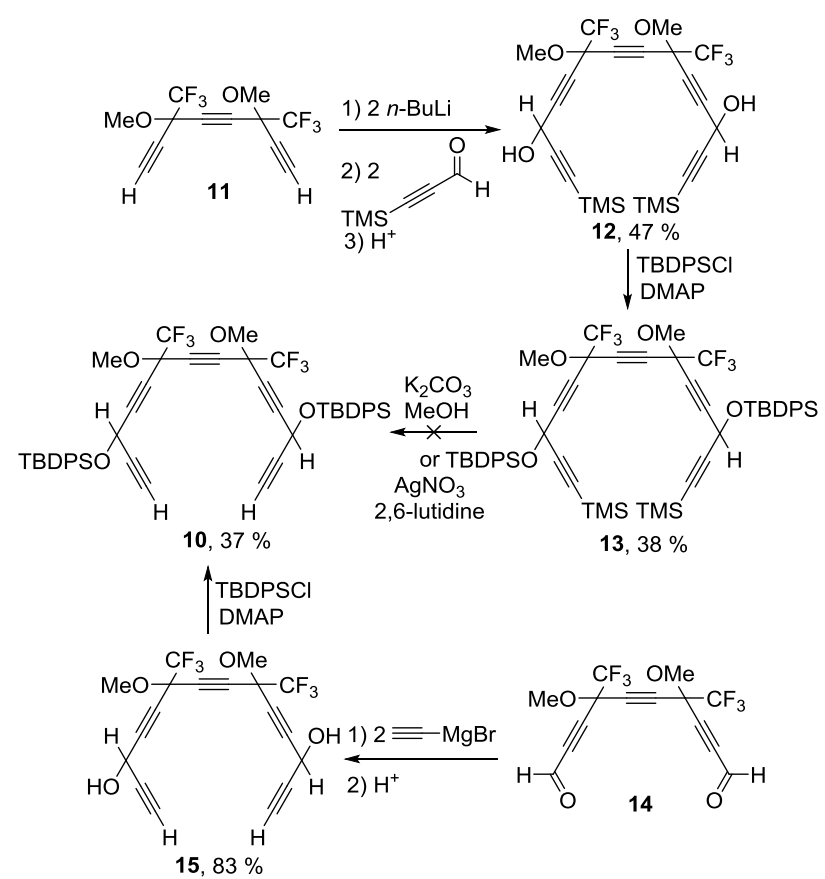

Scheme 3. Synthesis of the $C_{14}$ pentayne unit $\mathbf{1 0}$ for the proposed [14F+4] access to the [6]pericyclynediol 8 (Scheme 2). 
An alternative method was then precursor of the p-dianilinyl-carboenvisaged from the known dialdehyde 14, cyclohexadienic conductor $\mathbf{6}$, the [14F+4] prepared in two steps from the triyne 11 [5] strategy, unprecedented in the fluorinated series, (Scheme 3). The bis-terminal-pentaynediol 15 can now be reasonably envisaged from the $\mathrm{C}_{14}$ was first prepared in $84 \%$ yield by treatment of bis-terminal pentayne $\mathbf{1 0}$ and the $\mathrm{C}_{4}$ 14 with ethynylmagnesium bromide. The dibenzoylacetylene 9 (Scheme 4). targeted $\mathrm{O}$-protected $\mathrm{C}_{14}$ pentayne $\mathbf{1 0}$ was then obtained in $37 \%$ yield by treatment of $\mathbf{1 5}$ with TDBPSCl and DMAP.

A preliminary attempt at Improvements of the experimental conditions are currently being sought to achieve the challenging synthesis of the carbomacrocyclization performed between the dilithium salt of the $\mathrm{C}_{14}$ precursor $\mathbf{1 0}$ and the $\mathrm{C}_{4}$ diketone 9 provided an intractable polymeric mixture instead of the [6]pericyclynediol target 16 (Scheme 4). This result can be attributed to the high sensitivity of the lithiated intermediates. Working at lower temperature and over shorter reaction times should prevent polymerization and allow the isolation of $\mathbf{1 6}$, precursor of the pericyclynediol target $\mathbf{8}$ and ultimately of the key diketone 7.

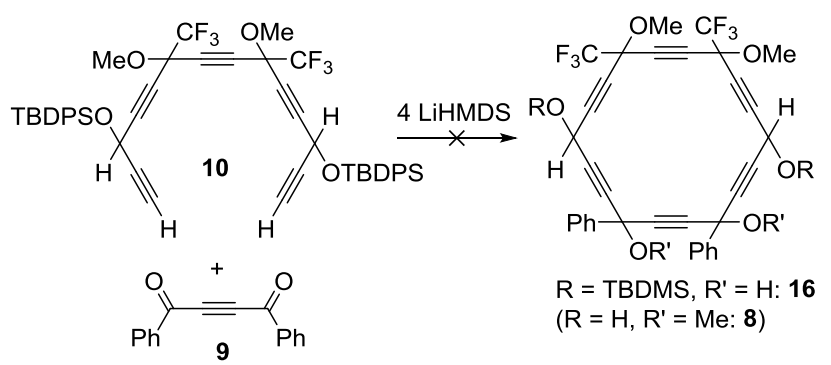

Scheme 4. First attempt at [14F+4] macrocyclization for the preparation of the [6]pericyclynediol $\mathbf{1 6}$.

\section{Conclusions}

As an alternative to the presently unproductive $[8+10]$ cyclization strategy towards the [6]pericyclynediol $\mathbf{8}$, putative cyclohexadiene $\mathbf{6}$ in view of the measurement of its SMC by STM-BJ.

\section{Experimental section}

General remarks. THF and diethyl ether were dried and distilled over sodium/benzophenone, dichloromethane (DCM) and pentane over calcium hydride. All others reagents were used as commercially available. Solutions of $n$ butyllithium were $2.5 \mathrm{M}$ in hexane. All reactions were carried out under argon atmosphere, using Schlenk and vacuum line techniques. Column chromatography were carried out on silica gel (60 A, C.C 70-200 $\mu \mathrm{m}$ ). Silica gel thin layer chromatography plates (60F254, $0.25 \mathrm{~mm}$ ) were revealed by treatment with an ethanolic solution of phosphomolybdic acid (20\%). The following analytical instruments were used, ${ }^{1} \mathrm{H}$ and ${ }^{13} \mathrm{C}$ NMR: Brüker Avance 300 and Avance 400 spectrometers; mass spectroscopy: Quadrupolar Nermag R10-10H spectrometer; IR: PerkinElmer Spectrum 100 FT-IR spectrometer. NMR chemical shifts are in ppm with positive values 
to high frequency relative to the tetramethylsilane reference for ${ }^{1} \mathrm{H}$ and ${ }^{13} \mathrm{C}$, and $\mathrm{CCl}_{3} \mathrm{~F}$ reference for ${ }^{19} \mathrm{~F}$. Coupling constants $J$ are in Hertz. Previously described procedures were used for the preparation of 9 [11], 11 [5] and $14[5]$.

Experimental procedures and characterizations.

10. To a solution of $15(0.10 \mathrm{~g}, 0.246$ $\mathrm{mmol})$ in dry DCM $(10 \mathrm{~mL})$ under stirring at r.t. were added first DMAP $(0.075 \mathrm{~g}, 0.616 \mathrm{mmol})$, then ClTBDPS (0.17 g, $0.616 \mathrm{mmol})$. After stirring for $3 \mathrm{~h}$ at r.t., the mixture was treated with a saturated aqueous $\mathrm{NH}_{4} \mathrm{Cl}$ solution. The aqueous layer was extracted with DCM, and the combined organic layers were washed with brine, dried over $\mathrm{MgSO}_{4}$ and concentrated under reduced pressure. The brown residue was purified by silicagel chromatography (pentane:acetone 95:5) to give $\mathbf{1 0}$ as a pale brown oil in $37 \%$ yield $(0.080 \mathrm{~g})$.

${ }^{1} \mathrm{H}$ NMR $\left(\mathrm{CDCl}_{3}, 400 \mathrm{MHz}\right): \delta=1.11(\mathrm{~s}, 18 \mathrm{H}$, $\left.\mathrm{SiC}\left(\mathrm{CH}_{3}\right)_{3}\right), 2.53(\mathrm{~s}, 2 \mathrm{H}, \equiv \mathrm{C}-\mathrm{H}), 3.51(\mathrm{~s}, 6 \mathrm{H}$, $\left.\mathrm{OCH}_{3}\right), 5.15$ (s, 2H, CHOSi), 7.38-7.48 (m, $12 \mathrm{H}, m$ - and $\left.p-\mathrm{C}_{6} H_{5}\right), 7.72-7.77(\mathrm{~m}, 8 \mathrm{H}, o-$ $\left.\mathrm{C}_{6} H_{5}\right) .{ }^{19} \mathrm{~F} \mathrm{NMR}\left(\mathrm{CDCl}_{3}, 376 \mathrm{MHz}\right): \delta=-79.16$, $-79.19\left(\mathrm{CF}_{3}\right) .{ }^{13} \mathrm{C}\left\{{ }^{1} \mathrm{H}\right\} \quad \mathrm{NMR} \quad\left(\mathrm{CDCl}_{3}, \quad 100\right.$ $\mathrm{MHz}): \delta=19.2\left(\mathrm{SiC}\left(\mathrm{CH}_{3}\right)_{3}\right), 26.5\left(\mathrm{SiC}\left(\mathrm{CH}_{3}\right)_{3}\right)$, $53.6\left(\mathrm{OCH}_{3}\right), 54.0(\mathrm{CHOSi}), 70.7(\mathrm{q}, J=35 \mathrm{~Hz}$, $\left.C-\mathrm{CF}_{3}\right), 73.2(\equiv C-\mathrm{H}), 73.3,78.4,79.7,86.1$ $(C \equiv C), 121.11\left(\mathrm{q}, J=283 \mathrm{~Hz}, C \mathrm{~F}_{3}\right), 127.8$, 127.9 (2s, $o$ - or $\left.m-C_{6} \mathrm{H}_{5}\right), 130.1,130.2\left(p-C_{6} \mathrm{H}_{5}\right)$, 131.9, $132.1\left(2 \mathrm{~s}, i-C_{6} \mathrm{H}_{5}\right), 135.7$ (o- or $m-C_{6} \mathrm{H}_{5}$ ).
MS (DCI/NH $\left.\mathrm{NH}_{3}\right): m / z: 900.3\left[\mathrm{M}+\mathrm{NH}_{4}\right]^{+} . \mathrm{FT}-\mathrm{IR}:$ v: 1859-2960 (C-H Ar), 2127 (三C-H), $1186(\mathrm{C}-$ O).

12. To a solution of the triyne $\mathbf{1 1}(0.240$ $\mathrm{g}, 0.805 \mathrm{mmol})$ in dry THF $(10 \mathrm{~mL})$ under stirring at $-78^{\circ} \mathrm{C}$ was added $n$-BuLi $(0.74 \mathrm{~mL}$, $1.85 \mathrm{mmol})$. The resulting mixture was stirred for $10 \mathrm{~min}$ at $-78{ }^{\circ} \mathrm{C}$, then $1 \mathrm{~h}$ at r.t. before cooling back to $-78{ }^{\circ} \mathrm{C}$. Then, a solution of trimethylsilylpropynal $(0.250 \mathrm{~g}, 2.00 \mathrm{mmol})$ in dry THF $(5 \mathrm{~mL})$ was added, and the mixture was kept under stirring at $-78{ }^{\circ} \mathrm{C}$ for $4 \mathrm{~h}$ before treatment with a saturated aqueous $\mathrm{NH}_{4} \mathrm{Cl}$. The aqueous layer was extracted with diethylether, and the combined organic layers were washed with brine, dried over $\mathrm{MgSO}_{4}$ and concentrated to dryness. The brown residue was purified by silicagel chromatography (Pentane:acetone 9:1), giving 12 as a pale brown oil in $47 \%$ yield (0.208 mg).

${ }^{1} \mathrm{H}$ NMR $\left(\mathrm{CDCl}_{3}, 400 \mathrm{MHz}\right): \delta=0.22(\mathrm{~s}, 18 \mathrm{H}$, $\mathrm{SiCH}_{3}$ ), 2.60 (bs, 2H, OH), $3.60\left(\mathrm{~s}, 6 \mathrm{H}, \mathrm{OCH}_{3}\right)$, 5.20 (bs, 2H, CHOH). ${ }^{19} \mathrm{~F} \mathrm{NMR}\left(\mathrm{CDCl}_{3}, 376\right.$ $\mathrm{MHz}): \quad \delta=-79.19-(-79.22)\left(\mathrm{CF}_{3}\right) .{ }^{13} \mathrm{C}\left\{{ }^{1} \mathrm{H}\right\}$ NMR $\left(\mathrm{CDCl}_{3}, 100 \mathrm{MHz}\right): \delta=-0.5\left(\mathrm{SiCH}_{3}\right)$, $52.3\left(\mathrm{OCH}_{3}\right), 54.0(\mathrm{CHOH}), 70.72(\mathrm{q}, J=36$ $\left.\mathrm{Hz}, C-\mathrm{CF}_{3}\right), 73.6,78.5,85.9,91.2,100.0(C \equiv C)$, $121.1\left(\mathrm{q}, J=283 \mathrm{~Hz}, \mathrm{CF}_{3}\right) . \mathrm{MS}\left(\mathrm{DCI} / \mathrm{NH}_{3}\right): \mathrm{m} / z$ : $568.1\left[\mathrm{M}+\mathrm{NH}_{4}\right]^{+}$. HRMS $\left(\mathrm{DCI} / \mathrm{CH}_{4}\right): \mathrm{m} / \mathrm{z}$ calcd for $\mathrm{C}_{24} \mathrm{H}_{27} \mathrm{O}_{3} \mathrm{~F}_{6} \mathrm{Si}_{2} \quad\left[\mathrm{M}-\mathrm{H}_{2} \mathrm{O}+\mathrm{H}\right]^{+}:$533.1403, found: 533.1386. FT-IR: v: $3395(\mathrm{O}-\mathrm{H}), 2961$ (C-H OMe), 2177 (C $\equiv \mathrm{C}), 1185$ (C-O). 
13. To a solution of $\mathbf{1 2}(0.140 \mathrm{~g}, 0.254$ $\mathrm{mmol})$ in dry DCM $(10 \mathrm{~mL})$ under stirring at r.t. were added DMAP (0.08 g, $0.636 \mathrm{mmol})$, and then CITBDPS (0.18 g, $0.636 \mathrm{mmol})$. After stirring overnight at r.t., the mixture was treated with saturated aqueous $\mathrm{NH}_{4} \mathrm{Cl}$. The aqueous layer was extracted with DCM, and the combined organic layers were washed with brine, dried over $\mathrm{MgSO}_{4}$ and concentrated under reduced pressure. The brown residue was purified by silicagel chromatography (pentane:DCM 9:1 then 7:3) giving $\mathbf{1 3}$ as a pale brown oil in $38 \%$ yield $(0.10 \mathrm{~g})$.

${ }^{1} \mathrm{H} \mathrm{NMR}\left(\mathrm{CDCl}_{3}, 400 \mathrm{MHz}\right): \delta=0.19(2 \mathrm{~s}, 18 \mathrm{H}$, $\left.\mathrm{SiCH}_{3}\right), 1.13\left(2 \mathrm{~s}, 18 \mathrm{H}, \mathrm{SiC}\left(\mathrm{CH}_{3}\right)_{3}\right), 3.55$ (2s, $\left.6 \mathrm{H}, \mathrm{OCH}_{3}\right), 5.19$ (2s, 2H, CHOSi), 7.42-7.50 $\left(\mathrm{m}, 12 \mathrm{H}, m-\right.$ and $\left.p-\mathrm{C}_{6} H_{5}\right), 7.76-7.84(\mathrm{~m}, 8 \mathrm{H}, o-$ $\mathrm{C}_{6} \mathrm{H}_{5}$ ).

${ }^{19} \mathrm{~F}$ NMR $\left(\mathrm{CDCl}_{3}, 376 \mathrm{MHz}\right): \delta=-79.10-(-$ 79.20) $\left(\mathrm{CF}_{3}\right) .{ }^{13} \mathrm{C}\left\{{ }^{1} \mathrm{H}\right\} \quad \mathrm{NMR} \quad\left(\mathrm{CDCl}_{3}, \quad 100\right.$ $\mathrm{MHz}): \delta=-0.5\left(\mathrm{SiCH}_{3}\right), 19.3\left(\mathrm{SiC}\left(\mathrm{CH}_{3}\right)_{3}\right), 26.5$ $\left(\mathrm{SiC}\left(\mathrm{CH}_{3}\right)_{3}\right), 53.9(\mathrm{CHOSi}), 54.2\left(\mathrm{OCH}_{3}\right), 70.8$ $\left.\left(\mathrm{q}, J=36 \mathrm{~Hz}, \mathrm{C}-\mathrm{CF}_{3}\right)\right), 73.0,78.4,86.4,90.4$, $100.7(C \equiv C), 121.2\left(J=284 \mathrm{~Hz}, C \mathrm{~F}_{3}\right), 127.7$, $127.8\left(2 \mathrm{~s}, o\right.$ - or $\left.m-C_{6} \mathrm{H}_{5}\right), 130.0,130.2(2 \mathrm{~s}, p$ $\left.C_{6} \mathrm{H}_{5}\right), 132.2,132.4\left(2 \mathrm{~s}, i-C_{6} \mathrm{H}_{5}\right), 135.7,135.8$ (2s, $o$ - or $\left.m-C_{6} \mathrm{H}_{5}\right)$. MS (DCI/NH $\left.\mathrm{NH}_{3}\right): m / z: 1044.2$ $\left[\mathrm{M}+\mathrm{NH}_{4}\right]^{+}$. FT-IR: v: 2859-2960 (C-H Ar), $2127(\mathrm{C} \equiv \mathrm{C}), 1185(\mathrm{C}-\mathrm{O})$.

15. To a solution of the dialdehyde $\mathbf{1 4}$ $(0.21 \mathrm{~g}, 0.59 \mathrm{mmol})$ in dry $\mathrm{Et}_{2} \mathrm{O}(20 \mathrm{~mL})$ under stirring at $0{ }^{\circ} \mathrm{C}$ was added ethynylmagnesium bromide (3.56 $\mathrm{mL}, 1.78 \mathrm{mmol})$. The stirring was maintained for $15 \mathrm{~min}$ at $0{ }^{\circ} \mathrm{C}$, then $3 \mathrm{~h}$ at r.t. before treatment with saturated aqueous $\mathrm{NH}_{4} \mathrm{Cl}$. The aqueous layer was extracted with $\mathrm{Et}_{2} \mathrm{O}$, and the combined organic layers were washed with brine, dried over $\mathrm{MgSO}_{4}$ and concentrated to dryness. The residue was purified by silicagel chromatography (pentane:acetone 7:3), giving 15 as a pale brown oil in $83 \%$ yield $(0.29 \mathrm{~g})$.

${ }^{1} \mathrm{H} \mathrm{NMR}\left(\mathrm{CDCl}_{3}, 400 \mathrm{MHz}\right): \delta=2.40(\mathrm{bs}, 2 \mathrm{H}$, $\mathrm{OH}), 2.65(\mathrm{~s}, 2 \mathrm{H}, \equiv \mathrm{C}-H), 3.60\left(\mathrm{~s}, 6 \mathrm{H}, \mathrm{OCH}_{3}\right)$, 5.24 (bs, 2H, CHOH). ${ }^{19} \mathrm{~F} \mathrm{NMR}\left(\mathrm{CDCl}_{3}, 376\right.$ $\mathrm{MHz}): \delta=-79.15,-79.16\left(\mathrm{CF}_{3}\right) .{ }^{13} \mathrm{C}\left\{{ }^{1} \mathrm{H}\right\} \mathrm{NMR}$ $\left(\mathrm{CDCl}_{3}, 100 \mathrm{MHz}\right): \delta=51.6\left(\mathrm{OCH}_{3}\right), 54.1$ $(C \mathrm{HOH}), 70.6\left(\mathrm{q}, J=36 \mathrm{~Hz}, C-\mathrm{CF}_{3}\right), 74.0(\equiv C$ $\mathrm{H}), 73.8,78.6,79.1,85.5(C \equiv C), 121.0(\mathrm{q}, J=$ $\left.283 \mathrm{~Hz}, C \mathrm{~F}_{3}\right)$. MS (DCI/NH $\left[\mathrm{M}+\mathrm{NH}_{4}\right]^{+}$. FT-IR: v: $3303(\mathrm{O}-\mathrm{H}), 2127$ (三CH), 1181 (C-O).

Acknowledgements. A.R. and the purchase of supplies and costs of analyses were supported by the ANR (11-BS07-016-01). O.L. was supported by the Ministery of Education and Science of Ukraine. The investigations were performed within the framework of the GDRI funded by the CNRS, Groupement FrancoUkrainien en Chimie Moléculaire.

\section{References}

[1] L. Leroyer, C. Lepetit, A. Rives, V. Maraval, N. Saffon-Merceron, D. Kandaskalov, D. Kieffer, R. Chauvin, Chem.-Eur. J. 2012, 18, 3226-3240. 


\section{[2]}

(a) R. Chauvin, Tetrahedron Lett. 1995, 397-400;

(b) V. Maraval, R. Chauvin, Chem. Rev. 2006, 106, 53175343.

[3] For references on pericyclynes see: (a) L. T. Scott, G. J. DeCicco, J. L. Hyun, G. Reinhardt, J. Am. Chem. Soc. 1983, 105, 7760-7761; (b) L. T. Scott, G. J. DeCicco, J. L. Hyun, G. Reinhardt, J. Am. Chem. Soc. 1985, 107, 6546-6555; (c) L. Maurette, C. Tedeschi, E. Sermot, M. Soleilhavoup, F. Hussain, B. Donnadieu, R. Chauvin, Tetrahedron 2004, 60, 10077-10098; (d) C. Saccavini, C. Tedeschi, L. Maurette, C. Sui-Seng, C. Zou, M. Soleilhavoup, L. Vendier, R. Chauvin, Chem.-Eur. J. 2007, 13, 4895-4913; (e) L. Leroyer, C. Zou, V. Maraval, R. Chauvin, C. R. Chimie, 2009, 12, 412-419.

[4] (a) R. Chauvin, C. Lepetit, V. Maraval, L. Leroyer, Pure Appl. Chem. 2010, 82, 769-800; for references on carbo-benzenes see: (b) Y. Kuwatani, N. Watanabe, I. Ueda, Tetrahedron Lett. 1995, 36, 119-122; (c) R. Suzuki, H. Tsukude, N. Watanabe, Y. Kuwatani, I. Ueda, Tetrahedron 1998, 54, 2477-2496; (d) R. Chauvin, Tetrahedron Lett. 1995, 36, 401-404; (e) C. Saccavini, C. Sui-Seng, L. Maurette, C. Lepetit, S. Soula, C. Zou, B. Donnadieu, R. Chauvin, Chem.-Eur. J. 2007, 13, 49144931; (f) C. Zou, C. Duhayon, V. Maraval, R. Chauvin, Angew. Chem. Int. Ed. 2007, 46, 4337-4341; (g) A. Rives, I. Baglai, V. Malytskyi, V. Maraval, N. Saffon-Merceron, Z. Voitenko, R. Chauvin, Chem. Commun. 2012, 48, 8763-8765; (h) I. Baglai, V. Maraval, C. Bijani, N. Saffon-Merceron, Z. Voitenko, Y. M. Volovenko, R. Chauvin, Chem. Commun. 2013, 49, 8374-8376.

[5] A. Rives, I. Baglai, C. Barthes, V. Maraval, N. Saffon-Merceron, Z. Voitenko, Y. Volovenko, R. Chauvin, Chem. Sci., 2015, 6, 1139-1149.

[6] B. Q. Xu, N. J. Tao, Science 2003, 301, 12211223 .

[7] Z. Li, M. Smeu, A. Rives, R. Chauvin, M. A. Ratner, E. Borguet, Nature Commun. DOI: 10.1038/ncomms 7321 .
[8] I. Diez-Perez, Z. H. Li, J. Hihath, J. H. Li, C. Y. Zhang, X. M. Yang, L. Zang, Y. J. Dai, X. L. Feng, K. Muellen, N. J. Tao, Nat. Commun. 2010, 1, 1-5.

[9] For references on carbo-butadienes see: (a) A. Rives, V. Maraval, N. Saffon-Merceron, R. Chauvin, Chem.-Eur. J. 2012, 18, 14702-14707; (b) A. Rives, V. Maraval, N. Saffon-Merceron, R. Chauvin, Chem.-Eur. J. 2014, 20, 483-492.

[10] Z. Z. Zhang, G. B. Schuster, J. Am. Chem. Soc. 1989, 111, 7149-7155.

[11] M. Journet, D. Cai, L. M. DiMichele, R. D. Larsen, Tetrahedron Lett. 1998, 39, 6427-6428. 